\title{
Analysis of inflammatory markers in apparently healthy automobile vehicle drivers in response to exposure to traffic pollution fumes
}

Hina Riaz ${ }^{1}$, Binafsha Manzoor Syed ${ }^{2}$,
Zulfigar Laghari ${ }^{3}$, Suleman Pirzad $a^{4}$

ABSTRACT

Objective: This study aimed to evaluate pattern of markers of inflammation in apparently healthy drivers who exposed to traffic fumes.

Methods: This cross-sectional study was conducted from June 2016 to January 2017 at Liaquat University of Medical \& Health Sciences (LUMHS), Jamshoro. It looked into the effects of traffic pollutants on markers of inflammation including CRP, Leukocytes count, IL-6, TNF- $a$, TNF- $B$ of healthy human volunteers. Eighty-seven, apparently healthy, non-smoking automobile vehicle drivers, having daily contact of traffic exhaust for at least six hours, aged between 18-40 years recruited for this study. Levels of traffic-generated pollutants P.M $M_{2.5}, P . M_{10}, N_{x}$ were recorded in different areas of Hyderabad City.

Results: P. $M_{2.5}$ found to be positively correlated with markers of inflammation including IL-6 $\left(r_{s}\right.$ $=0.99)$, TNF-a $\left(r_{s}=0.41\right)$, CRP $\mathrm{mg} / \mathrm{dl}\left(r_{s}=0.99\right)$, neutrophils $\left(r_{s}=0.29\right)$, lymphocytes $\left(r_{s}=0.31\right)$, eosinophils $\left(r_{s}=0.20\right)$, monocytes $\left(r_{s}=0.42\right)$ and basophils $\left(r_{s}=0.16\right)$. Positive correlation present among IL-6 $\left(r_{s}=0.21\right)$, TNF-a $\left(r_{s}=0.49\right)$ and CRP mg/dl $\left(r_{s}=0.22\right)\left(r_{s}=-0.31\right)$, Leukocytes $\left(r_{s}=0.14\right)$ neutrophils $\left(r_{s}=0.31\right)$, lymphocytes $\left(r_{s}=0.21\right)$, monocytes $\left(r_{s}=0.50\right)$, basophils $\left(r_{s}=0.17\right)$ with P.M $M_{10}$. $\mathrm{NO}_{\mathrm{x}}$ showed positive correlation with IL-6 $\left(r_{s}=0.22\right)$, TNF-a $\left(r_{s}=0.48\right)$, CRP $\left(r_{s}=0.22\right)$, neutrophils $\left(r_{s}=0.31\right)$, lymphocytes $\left(r_{s}=0.13\right)$, basophils $\left(r_{s}=0.17\right)$ and monocytes $\left(r_{s}=0.48\right)$.

Conclusion: Findings of our study suggest that almost all markers of inflammation are positively correlated with traffic pollutants and this condition might raise the risk of systemic diseases.

KEYWORDS: Traffic pollution, Healthy drivers, Markers of inflammation.

doi: https://doi.org/10.12669/pjms.36.4.2025

How to cite this:

Riaz H, Syed BM, Laghari Z, Pirzada S. Analysis of inflammatory markers in apparently healthy automobile vehicle drivers in response to exposure to traffic pollution fumes. Pak J Med Sci. 2020;36(4):657-662. doi: https://doi.org/10.12669/pjms.36.4.2025

This is an Open Access article distributed under the terms of the Creative Commons Attribution License (http://creativecommons.org/licenses/by/3.0), which permits unrestricted use, distribution, and reproduction in any medium, provided the original work is properly cited.

\section{INTRODUCTION}

Correspondence:

Dr. Hina Riaz,

Lecturer,

Department of Physiology,

Liaquat University of Medical and Health Sciences, Jamshoro,

Hyderabad, Pakistan.

Email: hina_riaz81@yahoo.com

* Received for Publication:

* $1^{\text {st }}$ Revision Received:

* $\quad 2^{\text {nd }}$ Revision Received:

* Final Revision Accepted:
November 28, 2019

December 11, 2019

February 26, 2020

March 3, 2020
Pakistan has been ranked among highly polluted countries of the world causing drastic effects on health, posing economic burden on the country., ${ }^{1,2}$ World air quality index 2019, reported that Lahore is the second and Karachi is the seventh most polluted cities of the world, recorded particulate matter (PM) concentration in Lahore and Karachi were $188 \mathrm{ug} / \mathrm{m}^{3}, 153 \mathrm{ug} / \mathrm{m}^{3}$ respectively. Approximately seven million early deaths have been reported around due to air pollution. Smog 
is the worst form of pollution comprised of fog, smoke of burning crops and traffic generated pollutants; every year Lahore is submerged with smog with first winter spell., ${ }^{2,3}$

Exposure to traffic pollutants such as $\mathrm{PM}_{2.5^{\prime}} \mathrm{PM}_{10}$ are associated with rise in mortality rate due to lung cancer and cardiovascular diseases. ${ }^{4}$ Study reported that prolong exposure to $\mathrm{PM}_{10}$, nitrogen dioxide $\left(\mathrm{NO}_{2}\right)$, sulphur dioxide $\left(\mathrm{SO}_{2}\right)$, carbon monoxide $(\mathrm{CO})$, is related with dyslipidemia, cardiac diseases (ischemic heart diseases, myocardial infarction) and diabetes mellitus. ${ }^{5}$ $\mathrm{PM}$ is one of the causative agents of neurological diseases by potentiating the oxidative damage in neural vasculature. ${ }^{6}$ Maternal Contact to $\mathrm{PM}_{2.5}$. $\mathrm{CO}, \mathrm{SO}_{2}$ and oxides of nitrogen $\mathrm{NO}_{x}$ is associated with preterm deliveries and low birth weight of infants and congenital abnormalities. ${ }^{7,8}$ Moreover prolong exposure to $\mathrm{PM}_{10}$ and $\mathrm{NO}_{2}$ is a causative factor of deaths in middle aged women due to cardiopulmonary diseases. ${ }^{9}$ It is reported by study that exposure of diesel exhaust potentiate the inflammatory process in human body which results in chronic diseases like asthma, cardiopulmonary disorders and cancers specially in susceptible population (children and elderly). ${ }^{10,11}$ Exposure of diesel exhaust fumes in infancy causes changes in gene expression of TNF, IL-10 and IL-13. ${ }^{12}$

As the traffic fume pollution is a global health concern, drastically affecting developing countries including Pakistan. however limited data is available till date to look into the pattern of markers of inflammation in apparently healthy population. Thus, this study was designed to evaluate the pattern of inflammatory markers in apparently healthy drivers who were exposed to traffic fumes. To the best of our knowledge, this is preliminary study in Pakistan that is addressing the effects of traffic exhaust fumes on human health.

\section{METHODS}

This cross-sectional study conducted from June 2016 to January 2017 at Liaquat University of Medical \& Health Sciences (LUMHS), Jamshoro. It looked into the effects of traffic pollutants on markers of inflammation of apparently healthy automobile vehicle drivers. Markers of inflammation including: C-reactive protein (CRP), Leukocytes count, interleukin-6 (IL-6), tumor necrotic factor- $\alpha$ (TNF- $\alpha$ ) and tumor necrotic factor- $\beta$ (TNF- $\beta$ ), total leukocyte and differential leukocytes count (neutrophils, lymphocytes, eosinophils, monocytes and basophils). For this study eighty-seven, apparently healthy, nonsmoking automobile vehicle drivers, having daily contact of traffic exhaust for at least six hours, aged between 18-40 years were recruited. Nonsmoking, apparently healthy, not suffering from any systemic disease or autoimmune diseases volunteers were included in this study. While volunteers suffering from any systemic disorders, autoimmune diseases, overweight person (BMI $\geq 30 \mathrm{~kg} / \mathrm{m}^{2}$ ) were not considered.

Methods of Inflammatory markers analysis: $3 \mathrm{ml}$ of whole blood was drawn from all the volunteers for analysis of inflammatory markers. CRP analyzed by "C-reactive protein Hitachi 902 turbidemetry "and total leukocytes count by "Automated Analyazer" (sysmex). While IL-6, TNF-a and TNF- $\beta$ were analyzed by "human instant ELISA (enzyme linked immunosorbent assay) (KOMA Biotech) ${ }^{\circledR}$ kits for analysis of markers. The standard laboratory method was followed, briefly $200 \mathrm{ul}$ of washing solution added to each well. Wells were aspired and excessive liquid removed 100 ul of standard (sample) then incubated at room temperature for two hours. Well aspirated and washed. $100 \mathrm{ul}$ of diluted detection antibody (0.4 $\mathrm{ug} / \mathrm{ml}$ for TNF- $\alpha, 0.1 \mathrm{ug} / \mathrm{ml}$ for TNF- $\beta$ and for IL-6 $0.25 \mathrm{ug} / \mathrm{ml}$ ) to each well covered with the plate sealer then incubated for two hours then diluted Color Development Enzyme (1:20 dilute) each well was added. Incubated at room temperature until the appropriate color development at least for 1727 minutes, plate read at $450 \mathrm{~nm}$ wavelength.

Exposure analysis: Measurement of pollutant (P.M ${ }_{2.5}$, P.M $_{10}$, and NOx) carried out at seventeen busy areas of Hyderabad (Sindh), where traffic flow is usually heavy. P.M Meter (Model Aerocet: 531) used for the analysis of $\mathrm{PM}_{2.5}$ and P.M $\mathrm{M}_{10}$ and $\mathrm{NO}_{x}$ Meter (Model: AC32M) for $\mathrm{NO}_{x}$ Level of pollutants compared with National Environmental Air Quality Standards (NEAQS). Concentration of each pollutant recorded at each location on three consecutive days of six months. Short duration exposure cut off value was five years $(\leq 5)$, while uppermost limit was twenty-five years $(\geq 25)$.

Statistical analysis: Data analyzed by using IBM statistical program for social sciences (SPSS), (IBM Corp. Released 2012. IBM SPSS Statistics for Windows, Version 23.0. Armonk, NY: IBM Corp. version) Spearman rank correlation used to determine the correlation of traffic pollutant with markers of inflammation. The results of all analyses evaluated for statistical significance using $\mathrm{p}$-value $<0.05$ and the $95 \%$ confidence intervals $(\mathrm{CI})$. 
Table-I: Mean concentration of pollutants of busy areas of Hyderabad City.

\begin{tabular}{lccc}
\hline Pollutants & $P . M_{2.5} \mathrm{ug} / \mathrm{m}^{3}$ & $P . M_{10} \mathrm{ug} / \mathrm{m}^{3}$ & $\mathrm{NOx} \mathrm{ug/ \textrm {m } ^ { 3 }}$ \\
\hline NEAQS Levels & 35 & 150 & 80 \\
Jamshoro level & 38.16 & 240.7 & 32.56 \\
$\quad$ crossing & & & \\
Qasim Intersection & 37.8 & 363.4 & 27.8 \\
Qasimabad & 40.16 & 263.6 & 40.5 \\
Civil Hospital & 43.4 & 234.1 & 35.6 \\
Hyder intersection & 42.3 & 257.3 & 28.5 \\
Chandni shopping & 44.2 & 233.5 & 41.23 \\
$\quad$ market & & & \\
Giddu intersection & 38.96 & 299.50 & 40.23 \\
\hline
\end{tabular}

Ethical consideration: The project was approved by the Ethical Committee of Liaquat University of Medical and Health Sciences (Ref No. LUMHS/ REC/94, dated Oct. 8, 2013) under the title: Detrimental Effects of Air Pollution on systemic health, Lung Volumes and Capacities of Young, Healthy Pakistani Volunteers.

\section{RESULTS}

During study period, 87 apparently healthy subjects included in the study. Mean age of subjects was $31( \pm 7.3)$ years. While mean height and mean weight were, $174 \mathrm{~cm}( \pm 4.8)$ and, $75 \mathrm{~kg}( \pm 6.3)$ respectively. Mean Body mass index (BMI) was, 24.3 (22.4). Mean concentration of $\mathrm{PM}_{25}$ (39.38), $\mathrm{PM}_{10}(254.18)$ and $\mathrm{NO}_{x}(37.26)$ recorded at different busy locations of city where traffic flow is quite high, compared with standard NEQS, as shown in Table-I mean levels of markers of inflammation are mentioned in Table-II.

P.M ${ }_{2.5 .}$ found to be positively correlated with following markers of inflammation; IL-6 $(r s=0.99, \mathrm{p}=0.001), \mathrm{TNF}-\mathrm{a}(r s=0.41, \mathrm{p}=0.001)$, CRP mg/dl $(r s=0.99, \mathrm{p}=0.001)$, neutrophils $(r s=0.29, \quad \mathrm{p}$-value $=0.006)$, lymphocytes

Table-II: Mean levels of markers of inflammation.

\begin{tabular}{lc}
\hline Markers of inflammation & Mean \\
\hline TNF-a pg/ml & 7.7 \\
IL-6 pg/ml & 60 \\
TNF- $\beta$ pg/ml & 29 \\
CRP mg/dl & 0.66 \\
Leukocytes & 9.1 \\
Neutrophils\% & 54 \\
Eosinophils \% & 5.0 \\
Basophils\% & 2.1 \\
Lymphocytes\% & 28 \\
Monocytes \% & 6.1 \\
\hline
\end{tabular}

Table-III: Spearmen Correlation in markers of inflammation and P.M $\mathrm{M}_{25}$

\begin{tabular}{lcc}
\hline Markers of Inflammation & \multicolumn{2}{c}{$P . M_{2.5} u g / m^{3}$} \\
\cline { 2 - 3 } & $r_{s}$ & $p$-value \\
\hline TNF-a pg/ml & 0.41 & 0.001 \\
IL-6 pg/ml & 0.99 & 0.001 \\
TNF- $\beta$ pg/ml & 0.47 & 0.66 \\
CRP mg/dl & 0.99 & 0.001 \\
Leukocytes & 0.03 & 0.73 \\
Neutrophils & 0.29 & 0.006 \\
Eosinophils & 0.20 & 0.006 \\
Basophils & 0.10 & 0.14 \\
Lymphocytes & 0.31 & 0.003 \\
Monocytes & 0.42 & 0.001 \\
\hline
\end{tabular}

$(r s=0.31, \quad$-value $=0.003)$, eosinophils $(r s=0.20, \mathrm{p}$-value $=0.06)$, monocytes $(r s=0.42$ $\mathrm{p}$-value $=0.001)$ and basophils $(r s=0.16, \mathrm{p}$-value $=0.14)$. While, there were no correlations present with total Leukocytes count $(r s=0.03, p$-value $=0.73)$, and TNF- $\beta(r s=0.47 \mathrm{p}$-value $=0.66)$ as shown in, Table-III.

There was a positive correlation present among IL-6 $(r s=0.21, \mathrm{p}=0.04), \mathrm{TNF}-\mathrm{a}$ $(r s=0.49, \mathrm{p}=0.001), \mathrm{CRP} \mathrm{mg} / \mathrm{dl}(r s=0.22, \mathrm{p}=0.03)$, Leukocytes $(r s=0.14$, p-value $=0.17)$ neutrophils $\% \quad(r s=0.31$, p-value $=0.003)$, lymphocytes $\%$ $(r s=0.21, \mathrm{p}$-value $=0.042)$, monocytes \% $(r s=$ 0.50$, p-value $=0.001)$, basophils \% $(r s=0.17$, $\mathrm{p}$-value $=0.11)$ with P.M $\mathrm{M}_{10}$. Whereas there was no correlation present with TNF- $\beta(r s=0.017$, $\mathrm{p}=0.66)$ and eosinophils $\%(r s=0.09, \mathrm{p}$-value $=$ 0.37 ), as shown in, Table-IV.

Markers of inflammation showed positive correlation with $\mathrm{NO}_{x}$ like; IL-6 $(r s=0.22, \mathrm{p}=0.03)$, TNF-a ( $r s=0.48, \mathrm{p}=0.001), \mathrm{CRP}(r s=0.22, \mathrm{p}=$ $0.03)$, leukocytes $(r s=0.14, p=0.18)$ neutrophils

Table-IV: Spearmen Correlation among markers of inflammation and P.M $\mathrm{M}_{10}$

\begin{tabular}{lcc}
\hline Markers of Inflammation & \multicolumn{2}{c}{$P . M_{10} u g / m^{3}$} \\
\cline { 2 - 3 } & $r_{s}$ & $p$-value \\
\hline TNF-a pg/ml & 0.49 & 0.001 \\
IL-6 pg/ml & 0.21 & 0.04 \\
TNF- $\beta$ pg/ml & 0.01 & 0.66 \\
CRP $\mathrm{mg} / \mathrm{dl}$ & 0.22 & 0.03 \\
Leukocytes & 0.14 & 0.17 \\
Neutrophils\% & 0.31 & 0.003 \\
Eosinophils \% & 0.06 & 0.37 \\
Basophils\% & 0.17 & 0.11 \\
Lymphocytes\% & 0.21 & 0.042 \\
Monocytes \% & 0.50 & 0.001 \\
\hline
\end{tabular}


Table-V: Spearmen rank Correlation among markers of inflammation and NOx.

\begin{tabular}{lcc}
\hline Markers of Inflammation & \multicolumn{2}{c}{ NOx ug/m $\mathrm{m}^{3}$} \\
\cline { 2 - 3 } & $r_{s}$ & $p$-value \\
\hline TNF-a pg/ml & 0.48 & 0.001 \\
IL-6 pg/ml & 0.22 & 0.03 \\
TNF- $\beta$ pg/ml & 0.02 & 0.82 \\
CRP mg/dl & 0.22 & 0.03 \\
Leukocytes & 0.14 & 0.18 \\
Neutrophils\% & 0.31 & 0.003 \\
Eosinophils \% & 0.10 & 0.34 \\
Basophils\% & 0.17 & 0.10 \\
Lymphocytes & 0.13 & 0.22 \\
Monocytes & 0.48 & 0.001 \\
\hline
\end{tabular}

$(r s=0.31, \mathrm{p}=0.003)$, lymphocytes $(r s=0.13, \mathrm{p}=$ $0.22)$, eiosinophils $(r s=0.10 p=0.34)$, basophils ( $r s$ $=0.17, \mathrm{p}=0.10)$, lymphocytes and monocytes ( $r s$ $=0.48, \mathrm{p}=0.001$ ). While no correlation was found with TNF- $\beta$ as shown in, Table-V.

\section{DISCUSSION}

According to findings of our study, most of markers of inflammation showed positive correlation with pollutants, Our study results have elaborated the Th1/Th2 derived pro inflammatory cytokines (TNF- $\alpha$, TNF- $\beta$ and IL-6), since the study population was healthy subjects increase in serum concentration at subclinical level is a frightening condition given that constant rise of inflammatory markers can lead to systemic diseases including autoimmune disease and even cancer. PM is highly hazardous for human health it is a combination of sulfate, sodium chloride, ammonia, mineral dust and black carbon. Due to its micro size it get lodge deep into lungs, along with $\mathrm{NO}_{\mathrm{x}}$ it causes irritation of respiratory mucosa and initiate local inflammation (TNF- $\alpha$, IL-6), diffusion of markers of inflammation transported into circulation and mediate systemic inflammatory cascade. Effects of traffic pollutants on respiration already discussed in a separate chapter of thesis.

In our study CRP showed positive significant correlation with pollutants $\mathrm{PM}_{2.5}$ and $\mathrm{PM}_{10}$, these findings are consistent with the results of Pilz (2018) study, in which $\mathrm{PM}_{2.5}, \mathrm{PM}_{10}, \mathrm{NO}_{2}$, and $\mathrm{NO}_{x}$ showed positive association with CRP on long term exposure. ${ }^{13}$ Similar results by Lee (2018), reported that short term exposure of pollutant like $\mathrm{SO}_{2}, \mathrm{NO}_{2}$ and $\mathrm{CO}$ causes increase in fibrinogen level in nonsmokers while, long term exposure causes rise in fibrinogen white blood cell (WBC) concentration. ${ }^{14}$ Study also revealed that short term exposure $\mathrm{NO}_{2}$ of non-smoking, healthy subject showed weak association with of markers of inflammation (IL6,CRP, TNF-a) while strong positive association found on long term exposure among non-smokers and physically healthy subjects. ${ }^{15}$ In our study monocytes showed significant positive correlation with PM, NOx and CO while increase in monocytes concentration at subclinical level after exposure to traffic related $\mathrm{NO}_{2}$ and $\mathrm{PM}$ as reported by another study. ${ }^{16}$ Another study reported that both coarse $\mathrm{PM}_{10}$ and fine $\mathrm{PM}_{2.5}$ enhanced monocytes antigen presenting capacity. ${ }^{17} \mathrm{PM}_{10}$ exposure to monocytes triggers increase intracellular calcium. ${ }^{18}$ Exposure of monocytes to nano particle of black carbon causes release of pro inflammatory cytokines (TNF-a, IL-6, IL-8) and increase in phagocytic capability of monocytes. ${ }^{19}$

Furthermore, diabetogenic biomarkers (adiponectin, interleukin-1 and CRP) found to be elevated in healthy non diabetic persons on short and long duration exposure of $\mathrm{PM}_{2.5}, \mathrm{PM}_{10}$ and $\mathrm{NO}_{2} \cdot{ }^{20} \mathrm{In}$ addition, one more study documented that $\mathrm{PM}_{2.5}$ exposure causes increase in serum concentration of CRP and neutrophils in nonsmoking healthy subjects ${ }^{21}$. Likewise a Nepali study revealed positive association of CRP with $\mathrm{PM}_{2.5}$ while, negative association reported with TNF- $\alpha$ and IL- $6 .{ }^{22}$ On the contrary a Belgian study reported no effects on total leukocytes concentration of healthy subject on exposure of traffic fumes and traffic related benzene causes decrease in WBC count, lymphocytes, eosinophils and platelets. ${ }^{23,24}$ Yet another study reported that when healthy female subjects exposed to pollutants for short duration CRP and leukocytes did not show positive association. ${ }^{25}$ A German study also stated prolong residential exposure of pollutant $\left(\mathrm{PM}_{2.5}\right)$, showed weak association with CRP and no any association on short duration exposure in non-smoking volunteers, ${ }^{26}$ in the same way a Californian study reported association of TNF- $\alpha$, IL- 6 and CRP with $\mathrm{NO}_{x}$ and $\mathrm{CO} .{ }^{27}$ Association of TNF- $\alpha$ with $\mathrm{NO}_{x}$ documented by another study..$^{28}$ In our CRP, IL-6 and TNF-a showed positive correlation with $\mathrm{PM}_{10^{\prime}}$ on the other hand Tsai (2019) conducted study in Switzerland exposed the general population to $\mathrm{PM}_{10}$ at low concentration; reported positive association of similar marker of inflammation while no significant association with CRP. ${ }^{29}$ 
Limitations of the Study: It incuded unavailability of continous air quality data, small smaple size and cross-sectional study design. However prospective nature of the study is a major strength besides having assessed environmental pollution at different areas of the study in order to confirm the exposure of the pollutant.

\section{CONCLUSION}

Findings of our study suggest that almost all markers of inflammation are positively correlated with traffic generated pollutants this condition might raises the risk of systemic diseases and causing deterioration health status of apparently of healthy subjects.

Recommendation: Pakistan has been ranked top most polluted countries of the world; at present country is facing distressing air quality index. Quite a few studies had reported air quality status of major cities of Pakistan but still lacking consistent data of country. There is critical need of such research projects on broad scale and large sample size. Joint projects with collaboration of environmental protection department should be conducted on urgent basis.

Acknowledgement: This study is part of $\mathrm{PhD}$ project of Dr. Hina Riaz, Funded by Liaquat University of Medical \& Health Sciences, Jamshoro. The authors are thankful to Department of Environmental Engineering \& Management and Department of Chemical Engineering of Mehran University of engineering and technology (MUET).

Grant Support E Financial Disclosures: This study is part of PhD project of Dr. Hina Riaz, Funded by Liaquat University of Medical \& Health Sciences, Jamshoro.

\section{Conflicts of interest: None.}

\section{REFERENCES}

1. Sanchez-Triana E, Enriquez S, Afzal J, Nakawaga A, Shuja Khan A. Air Pollution in Pakistan. eLibrary (World Bank Group). 2014;57-81. doi: 10.1596/978-14648-0235-5_ch2

2. Shahid J. Lahore, Karachi among top 10 most polluted cities in the world: WWF Pakistan DG. DAWN. 2018.

3. DESK BN. Lahore ranked second most polluted city on Oct 29. 2019.

4. Hvidtfeldt UA, Sorensen M, Geels C, Ketzel M, Khan $\mathrm{J}$, Tjonneland $\mathrm{A}$, et al. Long-term residential exposure to PM2.5, P Environ. Int M10, black carbon, NO2, and ozone and mortality in a Danish cohort. Environ Int. 2019;123:265-272. doi:10.1016/j.envint.2018.12.010
5. Shin J, Choi J, Kim KJ. Association between long-term exposure of ambient air pollutants and cardiometabolic diseases: A 2012 Korean Community Health Survey. Nutr Metab Cardiovas Dis. 2019;29(2):144-151. doi: 10.1016/j. numecd.2018.09.008

6. Wright J, Ding Y. Pathophysiological effects of particulate matter air pollution on the central nervous system. Environ Dis. 2016;1(3):85-89. doi: 10.4103/2468-5690.191932

7. Xiao $\mathrm{Q}$, Chen $\mathrm{H}$, Strickland $\mathrm{MJ}$, Kan $\mathrm{H}$, Chang $\mathrm{HH}$, Klein $\mathrm{M}$, et al. Associations between birth outcomes and maternal PM2.5 exposure in Shanghai: A comparison of three exposure assessment approaches. Environ Int. 2018;117:226-236. doi: 10.4103/2468-5690.191932

8. Wang L, Pinkerton KE. Air pollutant effects on fetal and early postnatal development. Birth Defects Res C Embryo Today. 2007;81(3):144-154. doi: 10.1002/bdrc.20097

9. Heinrich J, Thiering E, Rzehak P, Kramer U, Hochadel M, Rauchfuss KM, et al. Long-term exposure to NO2 and PM10 and all-cause and cause-specific mortality in a prospective cohort of women. Occup Environ Med. 2013;70(3):179-186. doi: 10.1136/oem.2004.016766

10. Krewski D, Jerrett M, Burnett R, Ma R, Hughes E, Shi Y, et al. Extended follow-up and spatial analysis of the American Cancer Society study linking particulate air pollution and mortality. Res Rep Health Eff Inst. 2009(140):5-114; discussion 136.

11. Manzetti S, Andersen O. Biochemical and physiological effects from exhaust emissions. A review of the relevant literature. Pathophysiology. 2016;23(4):285-293. doi: 10.1016/j.pathophys.2016.10.002

12. Gruzieva O, Merid SK, Gref A, Gajulapuri A, Lemonnier $\mathrm{N}$, Ballereau S, et al. Exposure to traffic-related air pollution and serum inflammatory cytokines in children. Environ Health Perspect . 2017;125(6):067007. doi: 10.1289/ EHP460

13. Pilz V, Wolf K, Breitner S, Rückerl R, Koenig W, Rathmann W, et al. C-reactive protein (CRP) and longterm air pollution with a focus on ultrafine particles. Int J Hyg Environ Health. 2018;(3):510-518. doi: 10.1016/j. ijheh.2018.01.016

14. Lee H, Myung W, Jeong B-H, Choi H, Jhun BW, Kim H Short- and long-term exposure to ambient air pollution and circulating biomarkers of inflammation in non-smokers: A hospital-based cohort study in South Korea. Environ Int. 2018;119:264-273. doi: 10.1016/j.envint.2018.06.041

15. Panasevich $S$, Leander $K$, Rosenlund $M$, Ljungman $P$, Bellander T, de Faire U, et al. Associations of long- and short-term air pollution exposure with markers of inflammation and coagulation in a population sample. Int J Occup Environ Med. 2009;66(11):747-753. doi: 10.1136/ oem.2008.043471

16. Su TC, Hwang JJ, Yang YR, Chan CC. Association Between Long-term Exposure to Traffic-related Air Pollution and Inflammatory and Thrombotic Markers in Middle-aged Adults. Epidemiology. 2017;28:S74-S81. doi:10.1097/ ede.0000000000000715

17. Becker S, Soukup J. Coarse (PM 2.5-10), fine (PM 2.5), and ultrafine air pollution particles induce/increase immune costimulatory receptors on human bloodderived monocytes but not on alveolar macrophages. J Toxicol Environ Health A. 2003;66(9):847859. doi: 10.1080/15287390306381

18. Brown D, Donaldson K, Stone V. Effects of PM 10 in human peripheral blood monocytes and J774 macrophages. Respir Res. 2004;5(1):29. doi: 10.1080/15287390306381 
19. Sahu D, Kannan G, Vijayaraghavan R. Carbon black particle exhibits size dependent toxicity in human monocytes. Int J Inflam. 2014;2014:827019. doi: 10.1155/2014/827019

20. Lucht S, Hennig F, Moebus S, Fuhrer-Sakel D, Herder $\mathrm{C}$, Jockel $\mathrm{KH}$, et al. Air pollution and diabetes-related biomarkers in non-diabetic adults: A pathway to impaired glucose metabolism? Environ Int. 2019;124:372-392. doi: 10.1016/j.envint.2019.01.005

21. Riediker M, Cascio WE, Griggs TR, Herbst MC, Bromberg PA, Neas L, et al. Particulate Matter Exposure in Cars Is Associated with Cardiovascular Effects in Healthy Young Men. Am J Respir Crit Care Med. 2004;169(8):934-940. doi:10.1164/rccm.200310-1463OC

22. Shakya KM, Peltier RE, Zhang Y, Pandey BD. Roadside exposure and inflammation biomarkers among a cohort of traffic police in Kathmandu, Nepal. Int J Environ Res Public Health. 2019;16(3):pii:E377. doi: 10.3390/ijerph16030377

23. Jacobs L, Nawrot TS, De Geus B, Meeusen R, Degraeuwe B, Bernard A, et al. Subclinical responses in healthy cyclists briefly exposed to traffic-related air pollution: an intervention study. Environmental Health. 2010;9(1):64. doi: 10.1186/1476-069X-9-64

24. Avogbe PH, Ayi-Fanou L, Cachon B, Chabi N, Debende A, Dewaele D, et al. Hematological changes among Beninese motor-bike taxi drivers exposed to benzene by urban air pollution. Afr J Environ Sci Technol. 2011;5(7):464-472.

25. Steinvil A, Kordova-Biezuner L, Shapira I, Berliner $\mathrm{S}$, Rogowski O. Short-term exposure to air pollution and inflammation-sensitive biomarkers. Environ Res. 2008;106(1):51-61. doi:10.1016/j.envres.2007.08.006

26. Hoffmann B, Moebus S, Dragano N, Stang A, Möhlenkamp S, Schmermund A, et al. Chronic Residential Exposure to Particulate Matter Air Pollution and Systemic Inflammatory Markers. Environ Health Perspect. 2009;117(8):1302-1308. doi:10.1289/ehp.0800362
27. Wittkopp S, Staimer N, Tjoa T, Gillen D, Daher N, Shafer $\mathrm{M}$, et al. Mitochondrial genetic background modifies the relationship between traffic-related air pollution exposure and systemic biomarkers of inflammation. PLoS One. 2013;8(5):e64444. doi: 10.1371/journal.pone.0064444

28. Mostafavi N, Vlaanderen J, Chadeau-Hyam M, Beelen R, Modig L, Palli D, et al. Inflammatory markers in relation to long-term air pollution. Environ Int. 2015;81:1-7. doi: 10.1016/j.envint.2015.04.003

29. Tsai DH, Riediker M, Berchet A, Paccaud F, Waeber G, Vollenweider $\mathrm{P}$, et al. Effects of short-and long-term exposures to particulate matter on inflammatory marker levels in the general population. Environ Sci Pollut Res Int. 2019;26(19):19697-19704. doi: 10.1007/s11356-019-05194-y

\section{Author`s Contribution:}

BMS, ZL and SP are supervisors of HR.

HR conceived, designed, data collection and did statistical analysis \& editing of manuscript, will be responsible and accountable for the accuracy or integrity of the work.

BMS supervised project, did review and final approval, editing of manuscript.

ZL supervised project, did review and final approval.

SP did review of manuscript.
Authors:

1. Dr. Hina Riaz, MBBS, Lecturer, Department of Physiology,

2. Dr. Binafsha Manzoor Syed, MBBS, PhD, Director Medical Research Centre, Director Clinical Research Division, Director ORIC,

3. Prof. Dr. Zulfiqar Laghari, PhD, Chairperson, Department of Physiology, University of Sindh, Jamshoro, Pakistan.

4. Dr. Suleman Peerzada, MBBS, PhD, Assistant Professor, Department of Molecular Biology and Genetics,

1,2,4: Liaquat University of Medical \& Health Sciences (LUMHS), Jamshoro, Pakistan. 